\title{
A model for implementing international networking within the pandemic conditions
}

\author{
Liubov Vyacheslavovna Kotsyubinskaya ${ }^{{ }^{*}}$, Larisa Vladimirovna Stakhova $^{1}$, and Yulia \\ Sergeyevna Avsiukevich ${ }^{2}$ \\ ${ }^{1}$ Pushkin Leningrad State University, Translation and Translation Studies Department, \\ Saint-Petersburg, Russia \\ ${ }_{2}^{2}$ International Business Communication Coaching, Tonbridge, United Kingdom
}

\begin{abstract}
The introduction of a network form of participants' interaction in the educational process, which gives a number of advantages in the implementation of educational programs, received a lively positive response from both universities and students. The possibility of academic mobility, which was (until recent times) an integral part of the network type of the educational process, allowed to increase the level of theoretical and practical training of students studying a foreign language. It contributed to the language immersion, which is necessary for the formation of communicative and socio-cultural competence in the learning process. The introduction of Coronavirus restrictions and, as a result, the closure of borders led to the impossibility of this component implementing. The study aims to develop a remote form of network interaction that contributes to the formation of necessary competencies among students studying a foreign language during a pandemic. The methods of pedagogical observation, experimental training, generalization and pedagogical modeling, as well as theoretical analysis of scientific achievements in the field of implementation of the traditional network form of education were used in the work. The fundamental principles of the remote organization of the educational process in a network form are highlighted; a model of the distance course "Academic Writing" (which is a component of the master's program "Theory of Translation and Intercultural Communication"), is developed; the format of remote network interaction in the framework of international cooperation with the British training center IBC Coaching in a pandemic is tested, the possibilities of using the developed model for teaching individual modules of other disciplines are considered (at the master's level and at the bachelor's level as well).
\end{abstract}

Keywords: international cooperation, educational field, network learning, pandemic, academic mobility, communicative competence

\section{Introduction}

${ }^{*}$ Corresponding author: 1.kocubinskava@lengu.ru 
The network form of the implementation of the educational program (EP) components offers a number of advantages for the participants of educational relations [1]. One of the success factors of the necessary competencies formation in the conditions of network interaction was (until recent times) the integration of full-time and distance learning. At the same time, priority was given to the in-person learning. Participating organizations actively practiced such a form of face-to-face interaction as academic mobility [2], which provided students with the opportunity to immerse themselves in the culture and language of a foreign-language society [3]. Modern conditions of the pandemic have made adjustments to the forms of organization of the educational process and influenced the choice of means of implementing network interaction. This process stimulated the search for new opportunities for online distance learning [4].

The hypothesis of the study is based on the fact that the introduction of the actual remote components of network interaction within teaching a foreign language determines the development of communicative and socio-cultural competence of students.

The relevance of the study, on the one hand, is due to the search for educational forms that can replace academic mobility while a pandemic. On the other hand, there is insufficient development of the implementing principles concerning the components of network interaction during the pandemic, as well as the lack of an educational and methodological base for implementing the form of network interaction in conditions of closed borders.

The aim of this study is to develop a model of network interaction in the implementation of the master's program "Theory of Translation and Intercultural Communication" modules.

This aim depends on these particular tasks:

1. To develop an algorithm for organizing network interaction.

2. To determine the technological component for the implementation of the network interaction model.

3. To determine the sequence of actions for the implementation of the remote form of the EP-module.

4. To test the developed model in the conditions of distance learning.

The study is novel in the adaptation of the components of network interaction, taking into account new historical conditions that hinder the implementation of the full-time format of network learning.

The practical significance of the study consists in the methodological development of the principles of implementing network interaction within a foreign partner while teaching a foreign language.

\section{Methods}

Theoretical and methodological basis go from the provisions presented in the literature on the methods of teaching foreign language [5, 6]; co-studying language and culture [7]; the networking principles [8-13].

Experimental base of the study was Pushkin Leningrad State University, the Foreign Languages Faculty, Department of Translation and Translation studies.

In order to solve the tasks, the following research methods were used: pedagogical observation, experimental training, theoretical analysis of scientific achievements in the implementation of the traditional network form of education, generalization and pedagogical modeling. 


\section{$3 \quad$ Results}

The course "Academic Writing" is part of the master's program "Theory of Translation and Intercultural Communication", implemented at the Foreign Languages Faculty of the Pushkin Leningrad State University. The teaching of this discipline is carried out by the British training center IBC Coaching with the help of distance learning technologies. The course aims to achieve academic literacy and culture in English by students through the formation of knowledge about academic discourse, concepts and strategies of academic writing, mastering the technologies of organizing the processes of creating, analyzing and editing academic text for successful research activities.

The learning model is presented in the form of a purposeful combination of synchronous and asynchronous processes of interaction between students and teachers by means of using distance learning tools using information and telecommunication technologies.

The organization of the educational process is based on the following five principles.

The Induction for Engagement Principle, which involves timely informing students about the organization of the course, goals, objectives, content, types of control, number of course hours, etc. This principle is implemented by creating an information booklet that contains the necessary information.

The Technical Accessibility principle, which means the time during which it is possible to access electronic resources online, on the one hand, and on the other - the choice of such programs and platforms for information exchange and video telephony, which would be the most convenient to use for all participants of the educational process and compatible with Mac and Windows operating systems.

The Flexibility Principle means that it is necessary to give the learning process the ability to change its focus in connection with the occurrence of unforeseen circumstances. This principle is connected with the Proactive Support Principle, the implementation of which allows you to postpone the time of classes if one of the participants has technical problems with the Internet.

The main aim of the Proactive Support Principle is to remove emerging technical problems and difficulties associated with completing tasks during the course, joining a video lecture, accessing resources and files. The implementation of this principle is ensured by providing students with the opportunity to contact the teacher by e-mail during and outside working hours, which allows not only to solve all difficulties in a timely manner, but also to stimulate the motivation of students to study and strengthen the relationships of participants in the educational process.

The Autonomy and Self-organization Principle presupposes an autonomous and self-controlled study of the issue after a teacher's briefing.

These principles are fundamental to the model of teaching academic writing as a distance learning course, which includes the following stages of learning implementation.

Stage 1. Organization. The purpose of the stage is to provide students with all the information necessary for the successful organization of the educational process, including the work program of the discipline.

Stage 2. Implementation of the discipline. This stage includes 4 components (Figure 1).

Step 1 - orientation session, the form of the video conference on the Zoom platform. At the end of this session, students receive recommendations for independent work, as well as a recording of the lecture and presentation materials. Task files are uploaded to Google Drive, which provides access to teaching materials at any time convenient for students. 
Step 2 - completing the assignment by students. At this stage, the principles of learning autonomy and proactive support are actively implemented, since students have the opportunity to contact the teacher by e-mail. Tasks must be completed and submitted on a certain date.

Step 3 - checking assignments by the teacher.

Step 4 - video-feedback. An individual video conference is organized, during which the completed task is discussed. The form of work is student - teacher. An audio sample and a general overview of completed tasks are also recorded, which is placed and placed on Google Drive.

\section{Step 4 \\ One-to-one video feedback online \\ (tutor - student)}

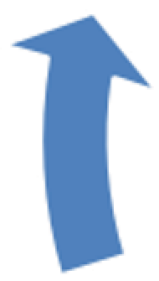

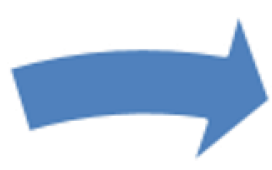

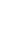

\section{Step 1 \\ Online video \\ lecture \\ (tutor - students)}

Step 3
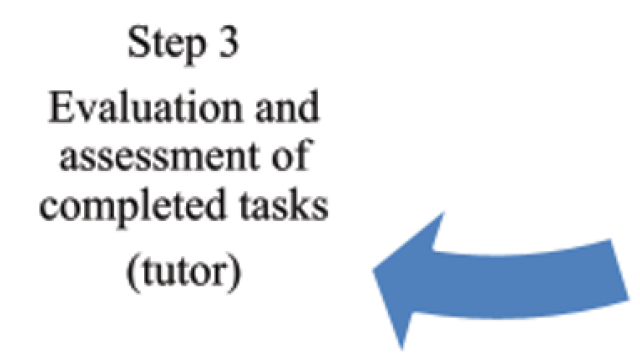

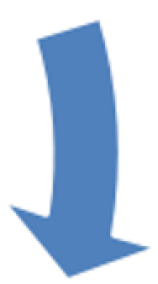

Step 2

Autonomous

learning and

assignment

completion

(students)

Fig. 1. The organizational sequence of the distance learning - course "Academic writing".

Stage 3. Control task. The control task consists of writing a literature review in English on the topic of a future master's thesis. This type of task synthesizes the skills and abilities acquired by students.

Currently, work is underway to modify this model for teaching individual modules of a number of other disciplines.

\section{Discussion}

Article No. 15 of the Federal Law of the Russian Federation of December 29, 2012, No. 273-FZ "On Education in the Russian Federation" initiated the introduction of a network form of educational programs in a number of educational institutions. As the universities of the Russian Federation have been testing a new form of conducting educational activities 
since 2014, a number of publications have appeared noting the advantages of this form of education compared to the traditional one, considering network training as the basis of affordable quality education $[9,10,14]$. The experience of implementing various means of online learning by leading Russian universities at the undergraduate, graduate and postgraduate levels is analyzed [11-13], the educational and methodological and regulatory framework for this type of pedagogical activity is being developed $[8,10,14]$.

One of the main components of networking, which is indicated in scientific papers, is the academic mobility of students, which contributes not only to immersion in the language environment, but also is a means of forming social and organizational identification of the individual. According to researchers, social identification, along with organizational identification, is a key factor uniting all participants in the educational process, contributing to the disclosure of the potential of students and the realization of their expectations $[15$, 16].

The formation of communicative and socio-cultural competencies, one of the fundamental requirements imposed by employers on graduates, is largely conditioned by the creation of conditions for a natural language environment $[5,6]$. Here it is possible to talk about the direct interaction of the student with native speakers of the language being studied. International cooperation, including academic mobility, served as a productive and effective tool for the formation of professionally oriented competencies of a future foreign language specialist $[17,18]$.

The introduction of coronavirus restrictions has radically changed all the forms of social interaction, including in the field of education [19]. The implementation of network learning models involving the integration of full-time and distance format becomes impossible in the context of a pandemic. In addition, self-isolation has led to the loss of social and organizational identification, which are an indispensable condition for productive learning activities [15]. There is a need to revise the methods and techniques of network interaction, to develop new algorithms of the educational process that allow replacing the face-to-face component of network interaction.

\section{Conclusion}

The developed algorithm makes it possible to successfully replace the full-time component of the online form of education in a pandemic. The adaptation of teaching materials to work with the help of a set of technical means allows for full-fledged professional interaction between the teacher and students.

\section{References.}

1. V. Ilie, E.S. Frăsineanu, Traditional learning versus e-learning, in European Proceedings of Social \& Behavioural Sciences EpSBS: the EDU WORLD 2018 The 8th International Conference, 193-1201 (2018). https://doi.org/10.15405/epsbs.2019.08.03.146

2. A.M. Egorychev, et al., Bul Novosib State Pedag Univ, 4(32), 29-38 (2016). https://doi.org/10.15293/2226-3365.1604.03

3. G.Z. Khabibullina, E.D. Shigapova, I.A. Rusanova, EpSBS: IFTE, 12, 83-88 (2016) https://doi.org/10.15405/epsbs.2016.07.14. 
4. Y.S. Romanova, et al., EpSBS, 111, 795-805 (2021). https://doi.org/10.15405/epsbs.2021.06.03.106

5. N.D. Galskova, M.N. Levchenko, V.P. Shabanova, N.A. Skitina, Astra Salvensis, 6(S), 797-805 (2018)

6. N.D. Galskova, Foreign Lang School, 4, 6-12 (2021)

7. F. Sharifian, Ethnoling. Prob Lang Cult, 28, 33-61 (2016). https://doi.org/10.17951/et.2016.28.31

8. A.V. Dozhdikov, Higher Edu Rus, 6, 11-19 (2015)

9. V.S. Dmitriev, V.S. Ivanova, K.V. Mertins, Int J Exper Edu, 7, 33-36 (2015)

10. N.V. Chicherina, O.D. Bugaenko, Higher Edu Rus, 10(205), 24-36 (2016)

11. E.A. Yarushkina, N.A. Chumakova, V.E. Bugaenko, ASU Bul, 2(180), 178-183 (2016)

12. E.A. Teplyashina, M.M. Petrova, A.B. Salmina, O.S. Razina, Edu Sci, 19(4), 118-129 (2017). https://doi.org/10.17853/1994-5639-2017-4-118-129

13. L.V. Kovtun, E. Solovova, E.S. Chilikina, O. Vygovskaya-Kazarina, Intercultural competence assessment in e-learning language course, in 5th international multidisciplinary scientific conference on social sciences and arts SGEM 2018: Conference proceedings, 461-468, Albena, Bulgaria, 26 August - 01 September, 2018 (Limited Liability Company STEPH 92 Technologies, Albena, 2018). https://doi.org/10.5593/sgemsocial2018/3.5/S13.058

14. A.B. Sobolev, Universum: Bul Herzen Univ, 3-4, 3-11 (2014)

15. S. Wilkins, M. Butt, D. Kratochvil, M. Balakrishnan, Stud Higher Edu, 41(12), 2232-2252 (2015). https://doi.org/10.1080/03075079.2015.1034258

16. M. Cheng, J. Taylor, J. Williams, K. Tong, Higher Edu Res Devel, 35(6), 1153-1166 (2016). https://doi.org/10.1080/07294360.2016.1160873

17. I.V. Lazutina, Bul Int Organiz, 1, 150-166 (2014)

18. L. Kotsyubinskaya, L. Stakhova, E. Listratkina, Academic Mobility As An Integral Component Of Modern Education, in The European Proceedings of Social \& Behavioural Sciences EpSBS: SCTCMG 2019 - Social and Cultural Transformations in the Context of Modern Globalism, 1791-1797 (2019). https://doi.org/10.15405/epsbs.2019.12.04.241

19. C.A. Gomes, S. Oliveira e Sá, E. Vázquez-Justo, C. Costa-Lobo, Ensaio: Aval. Pol. Públ. Educ 29(112), (2021). https://doi.org/10.1590/S0104-40362021002903296 